\title{
Assessing land requirements associated with UK food consumption: implications for food security and environmental sustainability
}

\author{
H. R. de Ruiter ${ }^{1,2}$, J. I. Macdiarmid ${ }^{3}$, R. B. Matthews ${ }^{1}$ and P. Smith ${ }^{2}$ \\ ${ }^{1}$ Information and Computing Sciences, James Hutton Institute, Aberdeen AB15 8QH, UK, ${ }^{2}$ Institute of Biological \& \\ Environmental Sciences, University of Aberdeen, Aberdeen AB24 2TZ, UK and ${ }^{3}$ Public Health Nutrition Research \\ Group, Rowett Institute of Nutrition and Health, University of Aberdeen, Aberdeen AB25 2ZD, UK
}

In a globalised world, the consumption and production of food are becoming increasingly disconnected ${ }^{(1)}$. This disconnection increases reliance on external resources and decreases the self-sufficiency of countries, and could have implications for population dietary health. Furthermore, population growth and global dietary change towards the consumption of more animal products are increasing the stress on already scarce global land resources ${ }^{(2)}$. As it is increasingly recognised that dietary recommendations should also consider the environmental impacts of our food consumption ${ }^{(3)}$, it is important to investigate the land requirements for food (LRF) of the current UK diet. This will not only contribute to our understanding of what comprises a sustainable diet; it will also show the degree of self-sufficiency of the United Kingdom.

Agricultural, food supply statistics and detailed trade flows for the year 2005, obtained from the Food and Agricultural Organization (FAO), were used to assess the LRF for the UK food consumption. Land requirements for animal products were calculated using animal specific feed conversion ratios and feed compositions ${ }^{(4)}$. Preliminary findings show that the average land requirement for the UK food supply equals $2,588 \mathrm{~m}^{2} /$ capita/year. More than $70 \%$ of these land requirements are related to the consumption of animal products, particularly ruminants (33\%). Total 'virtual' land use - i.e. the land embodied in the imports to the UK - equals 2.6 million hectare. Considering the total arable area available in the UK, this implies that the total imported area is $45 \%$ of total arable area in the UK.

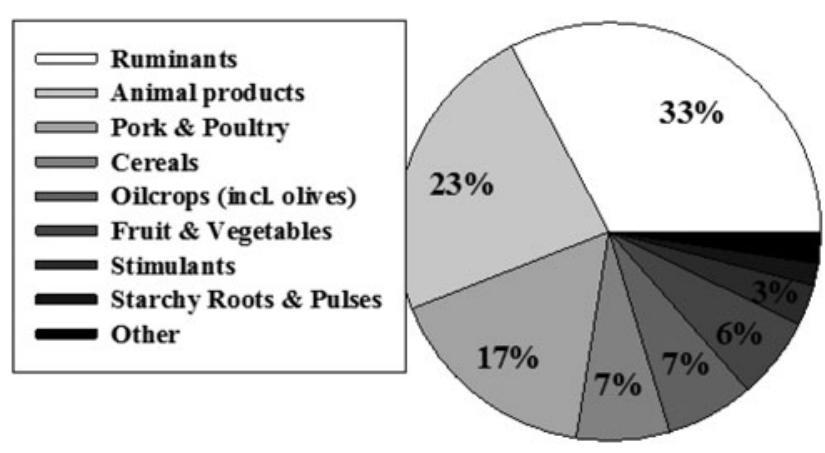

Fig. 1. LRF of UK food supply.

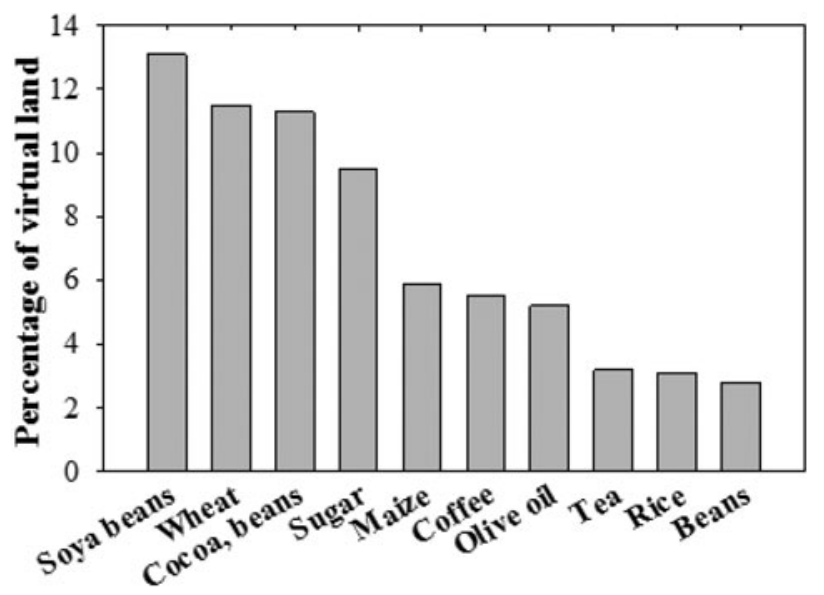

Fig. 2. Commodities responsible for virtual land use.

These results show that the land requirements of the UK diet are mainly related to the consumption of animal products, in particular ruminants. However, a substantial share in the land use of ruminants involves grasslands; land that is not always suited for human-edible crop production. The imported 'virtual' area is dominated by soya beans, which are primarily processed into oil (for human consumption), yielding cake as a by-product, which is used for animal feed. Other crops responsible for a large virtual land use include cereals, coffee and tea. A lower reliance on external land resources could thus also be achieved by a lower consumption of stimulants. Future research on scenarios of dietary change is needed to assess how a lower land appropriation can best be realised and still meet dietary recommendations.

1. Lambin EF \& Meyfroidt P (2011) Proc Natl Acad Sci U S A 108, 3465-3472.

2. Kastner T, Rivas MJI, Koch W, et al. (2012) Proc Natl Acad Sci U S A 109, 6868-6872.

3. Clonan A \& Holdsworth M (2012) Am J Clin Nutr 96, 459-460.

4. Wilkinson JM (2011) Animal 5, 1014-1022. 